\title{
Evaluation of some methods for the laboratory identification of Haemophilus infuenzae
}

\author{
GM TEBBUTT
}

From the Public Health Laboratory, South Cleveland Hospital, Marton Road, Middlesbrough, Cleveland TS4 3TA

SUMMARY Five tests-satellitism, synthesis of porphyrins, acid production from sucrose, $\beta$-galactosidase activity (ONPG), and indole production-to differentiate between strains of Haemophilus infuenzae and strains of V-dependent Haemophilus species were evaluated. Six per cent of strains of $H$ inftuenzae were misidentified as $H$ parainfuenzae by a test for satellitism using filter paper discs impregnated with $\mathrm{X}$ factor, $\mathrm{V}$ factor, or both, applied to Columbia Agar. None of seven nutrient agars tested grew Haemophilus species, and determined accurately the X factor requirement. Synthesis of porphyrins from $\delta$-aminolaevulinic acid provided a reliable means of demonstrating that $\mathrm{X}$ factor was required. A test for the production of acid from sucrose discriminated successfully between strains of V-dependent Haemophilus species (positive) and $H$ inftuenzae (negative). Most isolates were identified correctly by the ONPG test, but occasional $\mathrm{V}$-dependent strains were negative and could be misidentified as $H$ infuenzae. The discriminative value of the indole test was unsatisfactorily low. The results of the tests are discussed in relation to the identification of $H$ infuenzae in the diagnostic laboratory.

Haemophilus infuenzae, often part of the normal upper respiratory tract flora of man, can cause a wide variety of infections. ${ }^{1}$ With the exception of Haemophilus ducreyi, other members of the genus rarely cause human disease, but are frequently isolated from pathological specimens, such as sputum. In view of this difference in pathogenicity between $H$ inftuenzae and other species, a reliable method for the identification of $H$ infuenzae is essential.

By definition, Haemophilus species require haemin or certain other porphyrins (X factor) and/ or nicotinamide adenine dinucleotide (NAD) or certain co-enzyme-like substances ( $\mathrm{V}$ factor) for their multiplication. $H$ infuenzae requires both $\mathrm{X}$ and $\mathrm{V}$ factors for growth whereas most haemophili from the oral cavity are V-dependent. In the laboratory, these growth factor requirements are often determined by the application of paper discs containing $X$ factor, $V$ factor, or both, to different areas of a nutrient agar medium after it has been seeded with bacteria. Misidentification of $H$ influenzae based on the results of this test alone is not uncommon. ${ }^{2}$ Some nutrient agars contain sufficient $\mathrm{X}$ factor, and some factor may also be carried over in the inoculum, to

Accepted for publication 4 May 1983 enable the growth of $H$ infuenzae around the $\mathrm{V}$ factor disc. Other media fail to satisfy the exacting growth requirements of some haemophili, and the micro-organisms fail to grow around a disc containing $\mathrm{X}$ and $\mathrm{V}$ factors. A more reliable test to demonstrate a requirement for $\mathrm{X}$ factor is the porphyrin test. ${ }^{3}$ In this test, the synthesis of porphyrins from $\delta$-aminolaevulinic acid is demonstrated. Recently two biochemical tests, namely the production of indole from tryptophan, ${ }^{4}$ and the detection of $\beta$-galactosidase activity ${ }^{5}$ have been shown to be useful for discriminating between $H$ infuenzae and $H$ parainfuenzae. This study compares the results of the various tests for the identification of $H$ influen$z a e$, and assesses which tests are most suitable for use in a routine laboratory.

\section{Material and methods}

BACTERIAL STRAINS

The majority of strains were routine clinical isolates; 330 were from sputum, 48 from eyes, 55 from noses and throats, and seven from blood or cerebrospinal fluid (CSF). Sputum specimens were homogenised and processed as described by Tebbutt and Coleman. ${ }^{6}$ Isolates from blood or CSF were serotyped using a coagglutination test (Phadebact 
Haemophilus Test) obtained from Pharmacia (Great Britain) Ltd, Hounslow, Middlesex. Some strains, mostly V-dependent species, were isolated from throat swabs obtained from children in a paediatric ward and other strains came from throat swabs from patients in a geriatric ward. Type strains of $H$ infuenzae (NCTC 4560 and NCTC 8467) and $H$ parainfuenzae (NCTC 4101) were also included. Some isolates were snap frozen, and stored in liquid nitrogen suspended in nutrient broth with $10 \%$ (vol/vol) glycerol, before examination.

\section{CULTURE MEDIA}

Strains were isolated on Columbia Agar (Oxoid CM331) containing 5\% (vol/vol) horse blood, $10 \mathrm{mg} / \mathrm{l}$ NAD (BDH Chemicals Ltd, Poole, Dorset), and $10 \mathrm{mg} / 1$ haemin (BDH). For some throat swabs, $300 \mathrm{mg} / \mathrm{l}$ bacitracin (Mast Laboratories Ltd, Bootle, Merseyside) was added.

Media used to study the $\mathrm{X}$ factor requirement of Haemophilus species were as follows: (i) Columbia Agar (Oxoid); (ii) Proteose Peptone (2\% (wt/vol), Oxoid L46) solidified with $1 \%$ (wt/vol) agar (bacteriological grade, Oxoid); (iii) as in (ii) with $10 \mathrm{mg} / \mathrm{l}$ thiamine (Sigma Chemical Company Ltd, Poole, Dorset) added; (iv) Nutrient Broth (Oxoid CM1) solidified with $1 \%$ agar; (v) Nutrient Broth No 2 (Oxoid CM67) with 1\% agar; (vi) Brain Heart Infusion Agar (Oxoid CM375); and (vii) Blood Agar Base No 2 (Oxoid CM271). After autoclaving each medium was cooled to about $55^{\circ} \mathrm{C}$ and NAD $(10 \mathrm{mg} / \mathrm{l})$ was added. Haemin $(10 \mathrm{mg} / \mathrm{l})$ was also added in some tests. The media were stored at $4^{\circ} \mathrm{C}$, and used within one month of preparation.

\section{DETERMINATION OF X AND V FACTOR \\ REQUIREMENTS \\ Routine disc test}

Suspect colonies were inoculated onto Columbia Agar (without X and V factors) and spread over half the area of the plate with a sterile swab moistened in Nutrient Broth No 2. Discs containing $X$ factor, V factor, or both, (Mast Laboratories) were applied to different areas of the agar surface. Cultures were incubated overnight at $37^{\circ} \mathrm{C}$ in a moist atmosphere containing $5 \% \mathrm{CO}_{2}$ in air.

\section{Replicator method}

Bacteria were harvested into quarter-strength Ringer solution (Oxoid), and large clumps of bacteria were broken up by agitating the suspension for about $10 \mathrm{~s}$ on a Vortex mixer. Each suspension was adjusted so that it contained approximately $10^{8}$ bacteria/ml (barium sulphate standard number 1 ), and diluted a hundredfold in Ringer solution. A Denley multipoint inoculator (Denley Instruments
Ltd, Billingshurst, Sussex) was used to inoculate the 7 various nutrient agars with about $2 \times 10^{3}$ colony $\stackrel{0}{\overrightarrow{7}}$ forming units of each micro-organism. A surface $\frac{\text { ㅇ }}{2}$ viable count was performed on several strains to $\Rightarrow$ check inoculum size. Cultures were incubated in $5 \% \stackrel{\text { क }}{+}$ $\mathrm{CO}_{2}$ in air overnight at $37^{\circ} \mathrm{C}$. No growth or considerably diminished growth (minute colonies or a $\overline{\frac{5}{5}}$. slight haze) was recorded as a negative result.

\section{PORPHYRIN TEST}

The method described by Kilian ${ }^{3} 7$ was used. Before $\vec{\circ}$ reading the tests, samples were incubated at $37^{\circ} \mathrm{C} \overrightarrow{\vec{H}}$ for at least $4 \mathrm{~h}$. Porphyrins were detected by their $\stackrel{\sigma}{\sigma}$ typical red fluorescence under a Wood's lamp.

\section{BIOCHEMICAL TESTS}

Test reagents (see below) were stored in $5 \mathrm{ml}$ amounts at $-20^{\circ} \mathrm{C}$. For use, a $5 \mathrm{ml}$ sample was $\vec{\circ}$ thawed and kept for up to 7 days at $4^{\circ} \mathrm{C}$. Indole tests were performed in glass tubes (Dreyer's tubes) and $\vec{D}$ micro-titre trays were used for the other tests. For $\mathbb{D}$ each isolate, a heavy bacterial suspension was pre- $\underset{\mathbb{D}}{\mathbb{D}}$ pared in saline. Unless otherwise stated, $25 \mu \mathrm{l}$ of 3 suspension was added to $50 \mu$ l of test reagent.

\section{Indole production}

This was as described by Clarke and Cowan. ${ }^{8}$ Tese were incubated for $1 \mathrm{~h}$ or $2 \mathrm{~h}$ at $37^{\circ} \mathrm{C}$ before addō. tion of Kovács' reagent.

\section{$\beta$-galactosidase activity (ONPG test)}

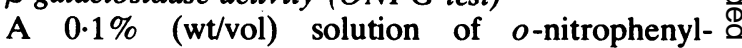
$\beta$-D-galactopyranoside (BDH) in $0.067 \mathrm{~mol} / 1$ phos- $\vec{\circ}$ phate buffer at $\mathrm{pH} 8.0$ was used.9 ${ }^{9}$ The results were 3 read after incubation for $1 \mathrm{~h}$ and $4 \mathrm{~h}$ at $37^{\circ} \mathrm{C}$ and $\supset$ after overnight incubation at room temperature.

\section{Production of acid from sucrose}

The method was similar to that described by Pick- $\frac{5}{3}$ ett $^{10}$ for characterising non-fermentative bacteria. The basal medium contained $5 \mathrm{ml}$ of dipotassium hydrogen phosphate $(0.5 \mathrm{~mol} / \mathrm{l}), 1 \mathrm{ml} \mathrm{pH}$ indicator solution (phenol red $(1 \% \mathrm{wt} / \mathrm{vol})$ and crystal violet 9 $(0.1 \% \mathrm{wt} / \mathrm{vol})$, and $0.5 \mathrm{~g}$ agar in $400 \mathrm{ml}$ distilled $\mathrm{D}$ water. The medium was stored at $4^{\circ} \mathrm{C}$. For use, a sample was removed and boiled for about $5 \mathrm{~min}$. For $\mathrm{N}$ each test, $25 \mu$ l of bacterial suspension, $50 \mu$ of basal medium, and $25 \mu \mathrm{l}$ of sucrose solution $(20 \%)$ $\mathrm{wt} / \mathrm{vol})$ were mixed. The tests were incubated at $\omega$ $37^{\circ} \mathrm{C}$ and read after four hours and then after overnight at room temperature.

\section{Urease activity}

Detection of - urease activity was carried out on $\frac{T}{\circ}$ indole-negative strains of $\boldsymbol{H}$ inftuenzae, using the 
Table 1 Effect of the medium on the growth and the $X$ factor requirement of Haemophilus species

\begin{tabular}{llll}
\hline Medium* & \multicolumn{2}{c}{ Percentage of total strains that grew on medium } \\
\cline { 2 - 3 } & V-dependent species & H infuenzae $\begin{array}{c}\text { H infuenzae, medium supplemented } \\
\text { with } X \text { factor }\end{array}$ \\
\hline Proteose Peptone & & 0 & 44 \\
Proteose Peptone + thiamine & 49 & 0 & 45 \\
Columbia & 78 & 6 & 97 \\
Nutrient Broth & 93 & 5 & 97 \\
Nutrient Broth No 2 & 65 & 6 & 99 \\
Brain Heart Infusion & 68 & 7 & 93 \\
Blood Agar Base No 2 & 75 & 5 & 98 \\
Total strains & 95 & 167 & 127 \\
\hline
\end{tabular}

*NAD (10 mg/l) added to all media.

method described by Lautrop. " After inoculation, each test was covered with sterile mineral oil. The results were read after incubation for $4 \mathrm{~h}$ at $37^{\circ} \mathrm{C}$.

\section{Ornithine decarboxylase activity}

This was looked for in indole-negative strains of $H$ infuenzae. The medium was similar to that described by Møller. ${ }^{12}$ After inoculation, mineral oil was added to each test. A control was included for each isolate tested. The results were read after incubation for $4 \mathrm{~h}$ at $37^{\circ} \mathrm{C}$ and then after overnight at room temperature.

\section{Results}

In this study, isolates which, showed satellite growth around an XV disc on Columbia Agar, were nonhaemolytic on horse blood agar, and which were unable to synthesise porphyrins from $\delta$-aminolaevulinic acid were considered to be $H$ infuenzae. Strains which grew around an XV disc on Columbia Agar, and which produced porphyrins from $\delta$-aminolaevulinic acid were called V-dependent Haemophilus species. Some of these $\mathrm{V}$-dependent species produced $\beta$-haemolysis.

During the period of study, $400 \mathrm{H}$ infuenzae strains were correctly identified from routine clinical specimens by the disc test. Forty isolates, which were considered to be possible pathogens, were provisionally identified as $H$ parainfuenzae. Other tests-porphyrin synthesis, ONPG, and acid produc- tion from sucrose-showed that of these strains 25 were $H$ influenzae. The disc test was repeated, and the growth of most of these strains in the vicinity of an XV disc was not clearly different from that around a disc containing $\mathrm{V}$ factor alone. A few strains grew better around the XV disc.

The influence of the medium on the growth and the $\mathrm{X}$ factor requirement of Haemophilus species is shown in Table 1. With the exception of agar containing Proteose Peptone, on which $44 \%$ of strains grew, strains of $H$ inftuenzae grew well on media supplemented with $\mathrm{X}$ and $\mathrm{V}$ factors (see Table 1). None of the strains of $H$ inftuenzae grew on Proteose Peptone agar containing $\mathrm{V}$ factor alone, but about $5 \%$ of the strains grew on the other media with $\mathrm{V}$ factor. Various results were recorded for strains of $H$ parainfuenzae with the different media. The majority of isolates grew on Columbia Agar and on Blood Agar Base No 2 supplemented with V factor, (93\% and $95 \%$ respectively), but less satisfactory results were obtained with the other media (Table 1). The recovery of $H$ parainfuenzae was improved by the addition of thiamine to Proteose Peptone agar (49\% to $78 \%$ of strains grew).

The indole and ONPG tests were usually positive after $1 \mathrm{~h}$ incubation at $37^{\circ} \mathrm{C}$. With some strains the ONPG test took $4 \mathrm{~h}$, and, for one strain, overnight incubation was required. Sometimes a small colour change was noted in the ONPG test after overnight incubation, and was ignored. The production of porphyrins and the formation of acid from sucrose

Table 2 Biochemical differentiation of $H$ infuenzae and $V$-dependent Haemophilus species

\begin{tabular}{llc}
\hline Test & \multicolumn{2}{c}{ Number (per cent) isolates that gave positive reactions } \\
\cline { 2 - 3 } & V-dependent species (porphyrin-positive) & H infuenzae (porphyrin-negative) \\
\hline Indole & $33(26)$ & $349(80)$ \\
ONPG & $101(80)$ & 0 \\
Sucrose & $122(97)$ & 0 \\
Total strains & 126 & 438 \\
\hline
\end{tabular}


occurred more slowly, but clear cut results were obtained, providing a heavy inoculum was used, after $4 \mathrm{~h}$ incubation.

Table 2 shows the results of biochemical tests with $438 \mathrm{H}$ infuenzae strains and $126 \mathrm{~V}$-dependent strains of Haemophilus species. The majority $(80 \%)$ of strains of $H$ infuenzae produced indole from tryptophan, but $26 \%$ of strains dependent on $\mathrm{V}$ only also gave a positive result. All seven isolates of $H$ infuenzae from blood or CSF produced indole, and six of these strains were capsulated, type b. One non-capsulated strain of $H$ inftuenzae was isolated from the blood of a patient with acquired agammaglobulinaemia. Indole-negative strains of $H$ inftuen$z a e$ were more likely to have been isolated from eyes $(15 / 48 ; 31 \%)$ than from sputum specimens $(61 / 330$; $18 \%)$. Sixty-nine per cent of indole-negative strains belonged to $H$ inftuenzae biotype III (urease positive, ornithine decarboxylase negative), as described by Kilian, ${ }^{7}$ and $21 \%$ to biotype IV (urease and ornithine decarboxylase positive). Eleven per cent of these strains were urease-negative and ornithine decarboxylase-positive, and probably represent a biotype additional to those described by Kilian.?

None of 438 strains of $H$ infuenzae produced acid from sucrose, and none gave a positive ONPG test (Table 2). In contrast, $122(97 \%)$ of V-dependent Haemophilus species produced acid from sucrose, and $101(80 \%)$ were ONPG positive. Although most V-dependent isolates were identified as $H$ parainfuenzae, 15 strains produced indole (12 of these were also ONPG positive) and could not be assigned to any species.

Sixteen isolates produced $\beta$-haemolysis on horse blood agar; of these strains, two were Haemophilus haemolyticus (XV-dependent) and 14 were dependent on $\mathrm{V}$ alone. Both isolates of $H$ haemolyticus produced indole, and did not produce acid from sucrose. One of the strains gave a positive ONPG test. All the haemolytic $V$-dependent strains produced acid from sucrose, two produced indole, and nine were ONPG positive.

\section{Discussion}

A test for satellitism is widely used to determine the growth factor requirements of Haemophilus species. $H$ inftuenzae grows on plain nutrient agar around a paper disc containing $\mathrm{X}$ and $\mathrm{V}$ factor, but fails to do so around a disc containing $\mathrm{X}$ or $\mathrm{V}$ factor alone. In practice, several workers have encountered difficulties in interpretation of the test. Kilian ${ }^{2}$ found $18 \%$ of $H$ infuenzae strains to be misidentified as $H$ parainfuenzae. He suggested that probably no complex medium, which otherwise satisfies the growth requirements of Haemophilus species, is completely free from $X$ factor. To some extent, the results of the present study confirm these findings Growth of $H$ infuenzae around a disc containing $V$. factor was relatively common, and may be due, in part, to carry-over of some $\mathrm{X}$ factor in the inoculum? Growth around the $\mathrm{V}$ disc, however, was often considerably less than that observed around a combine $\mathrm{XV}$ disc. Some strains showed no clear difference in the amounts of growth around $X$ and XV discs? Characteristically, these strains grew sparselyen around the discs, and nutrients other than $X$ and $V_{\circ}$ factors may be needed by the bacteria. Differences in nutritional requirements amongst strains of $H$ inftuenzae have bcen reported. ${ }^{13}$

This study confirmed that the determination of $x$ and $\mathrm{V}$ factor requirements for Haemophilus species is influenced by the variety of nutrient agar choseno for the test. Within the limitations of the test, Col- $\succcurlyeq$ umbia Agar appeared to be satisfactory. It should be noted, however, that, in these experiments, the inoculum size was controlled. Variations in the $\vec{c}$ numbers of micro-organisms seeded onto an again plate will influence the results of the test.

The demonstration of indole production has been suggested as a means of rapid, presumptive identification of $\mathrm{H}$ infuenzae. ${ }^{4}$ In this study, although $80 \%$ of $H$ infuenzae strains producesdo indole, some $26 \%$ of V-dependent species did same. It therefore seems unlikely that this test be accepted widely for the presumpties identification of $H$ influenzae.

In preliminary experiments, problems of repro: ducibility were encountered with sucrose fermenta- $-\propto$ tion tests, a phenomenon that has been describec previously. ${ }^{14}$ Variations in the quality of growth media may be responsible for this. Kilian, ${ }^{7}$ however? reported reproducible results with a commerciap fermentation medium, and the microtest describe के here gave rapid results that were easy to interpre? and reproduce. There was very good correlations between a positive sucrose test and the synthesis of porphyrins from $\delta$-aminolaevulinic acid. These ${ }_{3}$ findings suggest that the sucrose test may be of value for identification purposes.

The results of the ONPG test described here agreed with those of Kilian ${ }^{7}$ and contrasted slightlye. with those of Mehtar and Afshar. ${ }^{5}$ Of the $25 \mathrm{~N}$ $V$-dependent strains, which were ONPG negative five produced $\beta$-haemolysis and were differentiated easily from $H$ infuenzae. The other 20 strains, how- $\omega$ ever, would have been misidentified as $H$ infuenzae using the ONPG test alone.

This study has shown that, although problems of reproducibility with a test for satellitism can be ${ }^{-}$ minimised, some results are still difficult to inter -0 pret. A porphyrin or sucrose test distinguished suc- $-\frac{\mathbb{T}}{\mathbb{C}}$ 
cessfully between strains of $H$ infuenzae and those of other Haemophilus species isolated frequently in the routine laboratory. Both of these tests proved to be reliable, relatively easy to perform, and inexpensive. Although a heavy bacterial suspension is required, in practice, with the micromethods used here, this was rarely a problem. It should be noted, however, that these tests are not specific for the genus Haemophilus, and positive results will occur with some bacteria belonging to other genera. It is concluded that a porphyrin test or a sucrose test combined with identification to genus level will identify accurately $H$ infuenzae.

I thank Dr E McKay-Ferguson for reviewing the manuscript.

\section{References}

' Turk DC, May JR. Haemophilus infuenzae. Its clinical importance. London: English Universities Press, 1967.

${ }^{2}$ Kilian M. Haemophilus. In: Lennette EH, Balows A, Hausler WJ, Truant JP, eds. Manual of clinical microbiology 3rd ed. Washington: American Society of Microbiology 1980:330-6.

${ }^{3} \mathrm{Kilian} \mathrm{M}$. A rapid method for the differentiation of Haemophilus strains: the porphyrin test. Acta Pathol Microbiol Scand $[B]$ 1974;82:835-42.

4 Welch DF, Ahlin PA, Matsen JM. Differentiation of
Haemophilus species in respiratory isolate cultures by an indole spot test. J Clin Microbiol 1982;15:216-9.

${ }^{5}$ Mehtar S, Afshar SA. Biotyping of Haemophilus using API 10S-an epidemiological tool? J Clin Pathol 1983;36:96-9.

- Tebbutt GM, Coleman DJ. Evaluation of some methods for the laboratory examination of sputum. J Clin Pathol 1978;31:724-9.

${ }^{7}$ Kilian M. A taxonomic study of the genus Haemophilus, with the proposal of a new species. J Gen Microbiol 1976;93:9-62.

8 Clarke PH, Cowan ST. Biochemical methods in bacteriology. $J$ Gen Microbiol 1952;6:187-97.

' Kilian M, Frederiksen W. In: Kilian M, Frederiksen W, Biberstein EL, eds. Haemophilus, Pasteurella and Actinobacillus. London: Academic Press, 1981:282-91.

${ }^{10}$ Pickett MJ. Nonfermentative bacilli associated with man: II Detection and Identification. Am J Clin Pathol 1970;54:164 77.

"Lautrop H. Laboratory diagnosis of whooping cough or Bordetella infections. Bull WHO 1960;23:15-31.

12 Møller V. Simplified tests for some amino acid decarboxylases and for the arginine dihydrolase system. Acta Pathol Microbiol Scand 1955;36:158-72.

${ }^{13}$ Wolin HL. Defined medium for Haemophilus infuenzae type b.J Bacteriol 1963;85:253-4.

${ }^{14}$ Cowan ST, Steel KS. Manual for the identification of medical bacteria 2nd ed. London: Cambridge University Press, 1973:118.

Requests for reprints to: Dr GM Tebbutt, Public Health Laboratory, South Cleveland Hospital, Marton Road, Middlesbrough, Cleveland TS4 3TA, England. 